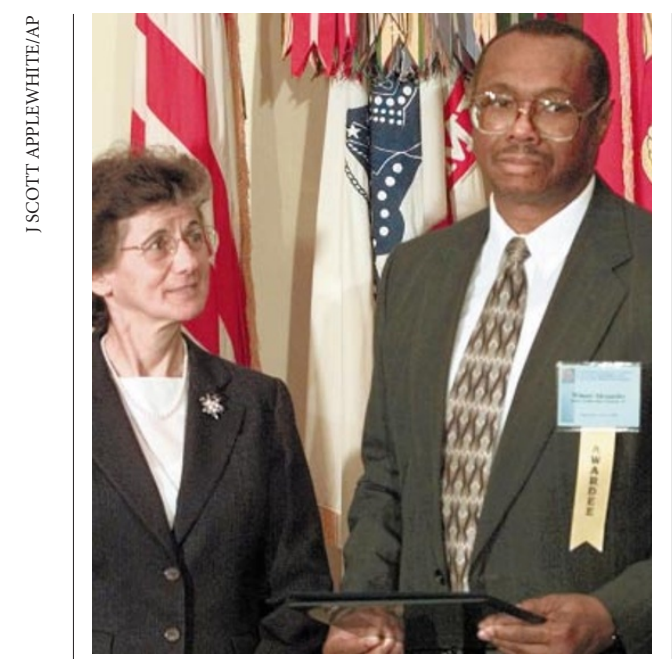

Excellence rewarded: NSF's Rita Colwell hands Winser E. Alexander an award for mentoring.

\section{Clinton seeks refuge} in calls for mentors to help minorities

[WASHINGTON] The beleaguered US president, Bill Clinton, has suggested that every scientist on a federal grant should be a mentor to guide minorities, women and disabled people into careers in science and technology.

At a ceremony at the White House last week to present the 1998 Presidential Awards for Excellence in Science Mathematics and Engineering Mentoring, Clinton said he was asking the National Science and Technology Council to look at ways "to achieve diversity throughout our scientific and technical workforce" and to report back to him within six months.

Clinton, who had just met with the senior Democrat senators whose support he needs to save a presidency now gravely imperilled by the Monica Lewinsky scandal, told the awardees that he "couldn't think of a better subject" than scientific mentoring for him to address "during this process that I'm going through".

Clinton said there were "tens of thousands of potential mentors" among university and laboratory scientists who are supported by the federal government. "If every one of them was to become a committed and dedicated mentor, think what that would mean," he said.

Arguing for more action to attract women and minorities into science, Clinton cited a report from the American Association for the Advancement of Science, which finds that the number of African Americans and Hispanics entering graduate science education fell by 20 per cent between 1996 and 1997.

The association says court rulings and moves by the University of California to end affirmative action have led to "an unwelcome environment" for minority graduate students, causing the decline. Colin Macilwain

\title{
Japanese institutes wary of increased autonomy
}

[TOKYO] Japanese scientists are expressing concern about the government's decision to carry out a large-scale reorganization of national research institutes attached to science-related ministries. The move will include transforming more than half of the institutes into semi-autonomous 'agencies' with administrative independence from the government (see Nature 389, 897; 1997).

The government says the change is needed to turn the institutes into genuine centres of excellence. But in late August an association representing the directors of Japan's 93 national research institutes released a report arguing that research institutes are fundamentally different from other government organizations, and that certain management procedures - especially those with strong emphasis on performance-related targets would be inappropriate for them.

The plan is part of the government's drive to improve the country's administration. The government says its plans to turn the institutes into semi-autonomous bodies is based on the 'Next Steps' strategy developed in the United Kingdom. Each institute will have a separate management system and an external assessment body made up of representatives from the private sector to evaluate its performance.

The administrative reform plan has taken a sluggish path since its approval in December. But it has advanced rapidly in the past month in the wake of the appointment of the new prime minister, Keizo Obuchi, who has pledged to start implementing the reforms as soon as possible.

Although individual ministries and agencies have started to draw up measures for reorganizing the national institutes, many are concerned that the views of scientists working in the institutes will not be given much attention.

Under the plan, 54 of the 93 national research institutes will be reorganized. These include the Science and Technology Agency's (STA)'s National Institute of Radiological Sciences, the Environment Agency's National Institute for Environment Studies, and all 15 institutes of the Ministry of International Trade and Industry's Agency of Industrial Science and Technology (AIST).

Institutes carrying out similar research are likely to be merged, and those with poor track records will be closed down before new agencies are formed.

But directors of national institutes have repeatedly voiced their concern about the plan. In particular, they point out that many of the institutes carry out basic research and are therefore unlikely to yield profitable returns. As a result, they argue, a management approach that emphasizes financial performance-related targets would become a burden on researchers.

“The government's effort to promote scientific research and its effort to rationalize the institutes seem to be conflicting with one another," says Shinichi Ohashi, director of AIST's National Institute of Biosciences and Human Technology.

The new status of the institutes would give them more flexibility in funding. For example, they would be able to carry over unspent research funds to the following fiscal year, in contrast to the current rules, under which annual funds must be used up within the year. But scientists are concerned that the change would make the institutes more vulnerable to cuts in government funding.

Michinori Nishio, chairman of the Association of Directors of National Research Institutes and director of the agriculture ministry's National Institute of Agro-Environmental Sciences, warns that, once institutes lose their direct links with government, they would also be in danger of losing a secure source of funding and have to start relying on other sources.

The association's report asks for continued funding for research institutes after their launch as agencies, and the Science and Technology Council (STC), Japan's main science policy-making body has urged the government to ensure that the new system does not affect the distribution of government funding to the institutes, even if they are free to obtain funding from external sources.

Despite government confidence that the reform will help the institutes to run more efficiently, many doubt that the new agencies will be any different from existing semigovernmental organizations (tokushu hojin), such as STA's National Space Development Agency and the former Power Reactor and Nuclear Fuel Development Corporation.

The tokushu hojin, which are funded by both the government and private sectors, have often been criticized for their poor management, lack of transparency, and inefficient use of funds. The Institute of Physical and Chemical Research (RIKEN) is the one exception that is widely seen to have made a success of the greater autonomy conferred by tokushu hojin status.

Previous attempts to reform these organizations have failed (see Nature 373, 551; 1995). STC's request states that the government would first have to reorganize the nation's semi-governmental organizations if they were to create real centres of excellence in Japan.

AsakoSaegusa 